\title{
TRABAJADORES EN MOVIMIENTO: DEL SINDICALISMO TRADICIONAL A LA ACCIÓN COLECTIVA ${ }^{1}$
}

\author{
Ernesto Sánchez Sánchez ${ }^{2}$ \\ https://orcid.org/0000-0001-5845-0600 \\ Renato Pintor Sandoval ${ }^{3}$ \\ https://orcid.org/0000-0003-3634-5011
}

\begin{abstract}
Recebido: 06.02.2020
Aceito: 13.04 .2020

Publicado: 06.07.2020

\section{RESUMEN}

El presente documento tiene como objetivo analizar, desde una mirada latinoamericana y a partir del contexto laboral, las nuevas relaciones que guardan el trabajador y sus formas contemporáneas de organización, negociación y reivindicación. Estas tienden a sujetarse a estándares de los mercados globales y del régimen neoliberal, la cual están sustentadas en la competitividad y el abaratamiento de la mano de obra. Se habla sobre este escenario laboralproductivo-organizacional dinamizando los mercados globales entre sí, facilitando las formas de inserción laboral y comercialización de la producción, sin embargo, se percibe una acentuación en las rupturas en las trayectorias laborales y una disolución de formas tradicionales de organización de trabajadores. La guía metodológica para el objetivo central de este escrito está sustentada en los marcos conceptuales sobre sindicalismo, organización del trabajo y acción colectiva, teniendo como marco territorial y temporal a México en la etapa neoliberal. El análisis se hace a partir de autores como Charles Tilly (2014), Alberto Melluci (1994) y Robert Castel (2010) y para el caso mexicano Enrique De la Garza (1993,2011,2014), Graciela Bensusán (2010) y Edtih Kuri (2016). A manera de conclusión se sostiene que, a la par los trabajos tradicionales y atípicos, son nuevas formas de organización y de identificación del trabajador, más allá del sindicalismo tradicional, conformando imaginativamente acciones colectivas que irradien más allá de los espacios laborales.
\end{abstract}

Palabras clave: México, organizaciones laborales, neoliberalismo, trabajo.

Trabalhadores em movimento: do sindicalismo tradicional à aç̧ão coletiva.

\section{RESUMO}

O presente documento tem como objetivo analisar, desde um olhar latinoamericano e a partir do contexto laboral, as novas relações que guardam o trabalhador e suas formas contemporâneas de organização, negociação e reivindicação. Estes tendem a sujeitar-se a padrões dos mercados globais e do regime neoliberal na qual estão baseados na competitividade e mão-de-obra mais barata. Se fala sobre esse cenário laboral-productivo-organizacional dinamizando os mercados globais entre si, facilitando as formas de inserção laboral e comercialização da produção, no entanto, se percebe uma acentuação das quebras nas trajetórias laborais e uma dissolução das formas tradicionais de organização de trabalhadores. A guia metodológica para o objetivo central deste escrito está baseada nos marcos conceituais sobre sindicalismo, organização do trabalho e ação coletiva, tendo como marco territorial e temporal o México na etapa neoliberal. A análises se faz a partir de autores como Charles Tilly (2014), Alberto Melluci (1994) y Robert Castel (2010) e para o caso mexicano Enrique De la Garza (1993, 2011, 2014), Graciela Bensusán (2010) e Edtih Kuri (2016). A maneira de conclusão argumenta-se que, ao mesmo tempo em que trabalhos tradicionais e atípicos, são novas formas de organização e de identificação do trabalhador, além do sindicalismo tradicional, conformando imaginativamente ações coletivas que irradiam além do espaço laboral.

Palavras chave: México, organizações laborais, neoliberalismo, trabalho.

Workers on the move: from traditional unionism to collective action.

\section{ABSTRACT}

The objective of this document is to analyze, from a Latin American perspective and from the labor context, the new relationships that workers have and their contemporary forms of organization. This tends to be subject to the standards of global markets and the neoliberal regime, which are based on competitiveness and the reduction of the cost of labour. This labor-productive-organizational scenario allows the dynamization of global markets among

1 Una parte de este documento emana del proyecto Profapi2015/267 Mundos del trabajo en Sinaloa. Proyecto financiado por la Universidad Autónoma de Sinaloa.

${ }^{2}$ Universidad Autónoma de Sinaloa. Correo electrónico: ernestoss@uas.edu.mx

${ }^{3}$ Universidad Autónoma de Sinaloa. Correo electrónico: rpintor@uas.edu.mx 
themselves, facilitating the forms of labor insertion and commercialization of production, however, what is perceived is an accentuation in the ruptures in labor trajectories and a dissolution of traditional forms of workers' organization. The methodological guide for the central objective of this document is based on the conceptual frameworks on trade unionism, work organization and collective action, having as a territorial and temporal framework Mexico in the neoliberal stage. The analysis is based on authors such as Charles Tilly (2014), Alberto Melluci (1994) and Robert Castel (2010) and for the mexican case Enrique De la Garza (1993, 2011, 2014) Graciela Bensusán(2010) and EdtihKuri (2016). In conclusion, it is argued that, alongside traditional and atypical jobs, new forms of organization and worker identification are needed, beyond traditional trade unionism, imaginatively shaping collective actions that radiate beyond the workplace.

Key words: Union, neoliberalism, labour, collective action

\section{Introducción}

La crisis en la dinámica estructural del capitalismo modificó las formas tradicionales de organización del trabajador. El neoliberalismo, proyecto por excelencia del capitalismo contemporáneo, impactó en los procesos de trabajo, y con ello a la clase trabajadora, con medidas que han disuelto, paulatinamente, las formas tradicionales de trabajo, las organizaciones y la representación gremial, así como la división social y sexual del trabajo. Sin embargo, como parte del mundo del trabajo, esto permitió nuevas formas de concebir al trabajo, de nuevas de organización y de reivindicaciones, así como la inclusión de nuevos agentes en las actividades del trabajo.

En este escenario, durante la década de los ochenta, los cambios en la sociedad mexicana, mostraron una dinámica de comportamiento heterogéneo, simbólico y vulnerable dentro del mundo del trabajo. En esta temporalidad se observó un panorama en que las condiciones laborales y sociales se situaron dentro de la flexibilidad, precarización y vulnerabilidad, sin condiciones de defensa o negociación para mejoras laborales, esencialmente por el desmembramiento y crisis sindical y otras formas de organización.

Con base a ello, el tema del presente artículo tiene como propósito analizar, desde el contexto laboral, las nuevas relaciones contemporáneas que se crean entre los trabajadores y sus formas de organización, negociación y reivindicación. Lo anterior refleja una metamorfosis en las relaciones laborales, que, evidentemente, muestran una innovación y replanteamiento, de manera incluyente e imaginativa, de nuevas vías y espacios para dar voz a los trabajadores, tradicionales y atípicos.

En este escrito se trata de conjuntar, analizar y describir, desde marcos referenciales y conceptuales sobre el neoliberalismo, trabajo, sindicato, acción colectiva y nuevos movimientos sociales, las formas cambiantes de organización de los trabajadores. Asimismo, se sitúa de manera breve el escenario mexicano y finalmente mostrar el común denominador global de la situación que enfrentan los trabajadores y sus organizaciones dentro de la etapa del capitalismo contemporáneo.

\section{Las organizaciones de los trabajadores en el neoliberalismo}

A finales del siglo XX se presentó prácticamente en toda Latinoamérica un modelo de crecimiento económico, político y social que acentuó graves problemas socioeconómicos en el mundo de trabajo, y esencialmente repercutió en las formas tradicionales de organización y representación que caracterizaron a la clase trabajadora. El comportamiento de la economía en esta región fue de lento crecimiento, con una creciente inequidad en la distribución de la riqueza, elevados índices de pobreza y de extrema debilidad y operatividad de las instituciones y agencias gubernamentales en la generación de riqueza. En este sentido, persistió el binomio globalización-neoliberalismo en la que se desarrolló una modernidad sistémica con valores sociales del capitalismo moderno, postindustrial, con características de violencia y marginación contra el trabajo digno y vivo, un deterioro del medio ambiente, migración laboral urbana y rural, y un desplazamiento de fuerza de trabajo que está dentro del rol de ejército industrial de reserva, en la que se suman las mujeres y niños, esto englobado, por el elitismo, exclusión y racismo, así como graves problemas ambientales (Gilly, 2014). Es decir, este sistema se desenvuelve dentro de crisis económicas recurrentes que acentúan las transformaciones políticas, sociales y culturales y trastocan el poder real de las organizaciones de trabajadores, los sindicatos y otras formas de organización laboral. 
En este sentido, en la etapa neoliberal el sindicalismo cambió las formas de coaptación y corporativismo que lo presentaban como institucionalizado y tradicional. Este entró en crisis durante los años ochenta, erosionando las características esenciales operativas de negociación colectiva y una fuerte politización y militancia, como fue el caso mexicano. Esta situación también fue resultado de la crisis del Estado social benefactor en la cual hubo una reducción del impacto de los pactos corporativos y, por lo tanto, una disminución de la influencia sindical en la gestión del sistema de relaciones industriales, sustentada en la descentralización y flexibilización (Hyman, 1989 en De la Garza, 2014).

Lo anterior no se puede entender sin los cambios en las relaciones industriales tradicionales. Las transformaciones en la economía global y neoliberal, produjeron una reestructuración productiva en sintonía con la nueva revolución tecnológica o digital y cambios organizacionales. Esto impactó en las relaciones laborales relegando a los sindicatos y otras formas de organización gremial.

Asimismo, los mercados de trabajo se caracterizaron, hasta nuestros días, por la presencia creciente del empleo informal, precario, atípico, de tiempo parcial, con vulnerabilidad social, constituido por mano de obra no calificada y segmentada, que hace cada vez más difícil agrupar gremialmente y postular reivindicaciones propias de las luchas sindicales tradicionales (De la Garza, 2011, 2014).Si esto se observa desde la perspectiva global, los sindicatos y otras organizaciones de trabajadores, tradicionales y atípicos, se enfrentan a un paisaje en el que los mismos Estados-nación, en conjunción con la transnacionalización empresarial, promueven la flexibilización laboral y el outsourcing, y paulatinamente desmantelan las protecciones de seguridad social en nombre de la productividad, competitividad y calidad, sin condiciones para construir trayectorias laborales continuas y sólidas, es decir, proyectos biográficos laborales estables con base a los planes de vida del trabajador.

Con relación a lo anterior, Negri y Hardt (2002) de manera integral señalan que la globalización facilita el traslado de capitales entre regiones o países garantizando de manera óptima el proceso de acumulación de capital a través de la fragmentación de los procesos productivos modificando un conjunto de relaciones laborales, sociales y culturales. Para el caso mexicano que, desde la etapa posrevolucionaria hasta la implementación del neoliberalismo, el Estado tuvo un papel fundamental en el desarrollo económico a la par del impulso del proceso industrializador de sustitución de importaciones, donde la figura central fue el nacionalismo económico-cultura de la dependencia, y con referencia notoria en el papel activo del trabajador rural e industrial como eje de la acumulación de capital en México (Rodríguez, 2009). En ese periodo se permitió a las organizaciones sindicales, fuertemente politizadas, a controlar al trabajador a través del corporativismo y la política de masas. En esta dinámica, entre el Estado y trabajadores, se incluyó el reconocimiento de derechos y prestaciones en materia de previsión social, que más allá del corporativismo y control hacia los trabajadores, se administraron conflictos y, a su vez, empoderaron a organizaciones gremiales capaces de negociar y pactar con el Estado y el bloque patronal. Es por ello que, a pesar del control y dominio del Estado sobre gran parte de las organizaciones y confederaciones gremiales mexicanas, existía, a pesar de las limitaciones y control partidista, un espacio de discusión, negociación y coordinación de políticas salariales y seguridad social, pero que mínimamente garantizaban una continuidad en la trayectoria laboral del trabajador, sin olvidar, el control político electoral, o bien de corporativismo y clientelismo (Cerdas, 2014; Zapata, 2000). Para Ortega y Solís (2005, p. 38) esto funcionaba como fuerza de choque del Estado para mantener el equilibrio en sus relaciones con los trabajadores subalternos, es decir, los grandes bloques sindicales existían como una forma de organización centralizada ante un Estado promotor del desarrollo industrial.

Entonces, a partir de la desaparición paulatina en estas formas del trabajo y organización de trabajadores, se acentúo un escenario laboral agresivo, por lo que surgió un sindicalismo independiente con nuevas formas de entender "ser trabajador", ya no sólo por la reducción en la capacidad de negociación y luchas, sino también por la aparición de aquellos insertos en trabajos 
atípicos, no industriales, que no se encuadran a estructuras tradicionales de organización laboral y buscan formas de reconocimiento y representación por la defensa de derechos laborales.

Se debe hacer énfasis en que esta situación no sólo está enmarcada a la cuestión de la organización del trabajo, sino, además, es una condición sistémica, creando escenarios de precarización más allá del espacio laboral, y genera una ruptura en la relación entre empleo- inclusión- integración social, y trastoca de manera negativa la condición de ciudadanía con plenos derechos. Por lo tanto, estamos ante una contraposición del trabajo digno y decente, que se enmarca en la seguridad en el empleo, al reconocimiento social, derechos laborales y seguridad social. Para Lorey (2016, p. 48) si esto se observa a gran escala, se percibe la conformación de sujetos modernos, sobrepasando lo tradicional y, bajo el esquema más inclusivo de ciudadanía, se encuadran en el binomio biopolíticagubernamental en la cual se conjuga una dualidad de subyugación y empoderamiento, por parte del mismo Estado y por el ciudadano-trabajador.

Con esto se quiere decir que hay un cambio del régimen del capital, ahora neoliberal, y como sistema dinámico modifica las formas de producir, intercambiar y regular, profundizado serias desigualdades con base a las formas de lucha, representación y organización de los trabajadores. En esta tesitura es pertinente la postura de Castel (2010, pp.18-19) al señalar que el sistema capitalista regulaba y sostenía las desigualdades que afectaban al trabajador, pero estas mismas dejaron de ser eminentemente laborales, puesto que también son parte de una cuestión social, es decir, el trabajador es portador de derechos políticos, más allá de ubicarlo dentro de la esfera de la producción y de cambio organizacionales.

Es decir, la continuidad del capitalismo neoliberal profundizó, no sólo las diversas formas de inserción laboral, sino que acentúo una crisis de representatividad del sindicalismo corporativo, delimitado por un sindicalismo patronal y neocorporativo, dejando de tener influencia y negociación con el Estado y la elite empresarial (Ortega y Solís, 2005, p.158). Por lo que hay un sometimiento excluyente a la política laboral institucional, disminución de espacios políticos y de negociación en políticas públicas ${ }^{4}$. Es decir, el Estado, de manera gradual, desapareció como el eje regulador, de control y protección hacia el sector empresarial. Además, dejó a otros sectores, de la iniciativa privada, espacios claves que modifican la condición del ciudadano-trabajador en la educación, seguridad social, medio ambiente, el patrimonio cultural y demandas por las mujeres trabajadoras y trabajo infantil.

Para el caso mexicano, como señala Escobar (2019, p.242), históricamente se presentó un sistema corporativo, en cual el Estado controló y coaptó políticamente a las agrupaciones gremiales a través de cambios en las estructuras legales e institucionales, pero también implementaron beneficios como garantizar trabajos estables, aumentos salariales, prestaciones y seguridad social, evidente enmarcado en un contexto de antidemocracia sindical.

Posteriormente, ya con la instauración del neoliberalismo, aquel pacto social que existía se modificó iniciando con topes al incremento salarial y debilitando la capacidad de negociación de las organizaciones gremiales, proliferando los contratos de protección que se pactaron jurídicamente sin conocimiento de los trabajadores, con prestaciones y derechos mínimos carentes de toda negociación legítima, acentuando el control salarial y la subcontratación, es decir, relaciones labores al margen de un Estado de derecho (Escobar, 2019).

Lo anterior tiene relación con lo planteado por Castel (2010) al señalar una metamorfosis entre la relación del Estado con el trabajador, y que, si antes se garantizaba seguridad y la protección, ahora paradójicamente es fuente de peligro y de amenaza, que configura un proceso de precarización caracterizado por la inseguridad e incertidumbre. Por ello, para este autor la condición de

\footnotetext{
${ }^{4}$ La continua y progresiva debilitación de los sindicatos u otras formas de organización por parte de trabajadores tiene como causas, no sólo la desaparición del empleo a causa de la extensión y los avances tecnológicos, sino esencialmente con base a que el modelo neoliberal configuró la esencia del Estado, a partir de nuevas formas de sentirse trabajador, principalmente desde la atomización e individualismo y la competitividad.
} 
precariedad e incertidumbre está en función también del rol del Estado social que proporcionaba cierta protección al ciudadano-trabajador.

Con este paisaje es entendible la aparición de organizaciones de trabajadores, uniones o colectivos no necesariamente como sindicales tradicionales, que se plantean un proyecto alternativo al neoliberalismo, algunos desde la militancia ideológica partidista, y otros desde el activismo civil y señalan nuevas formas de concebir al trabajo y sus relaciones sociales, más allá de lo laboral, es decir, conceptualizan un proyecto de largo aliento que modifica, de manera integral y positiva, las condiciones y relaciones del trabajador. En este tenor, las situaciones de crisis de representatividad sindical, permiten ampliar las formas de interacción por parte de los trabajadores, clásicos y atípicos, extendiendo las demandas y reivindicaciones culturales, sociales, simbólicos, políticos y ecológicas (Jodar y Marín-Artiles y Alós, 2004). Dicho de otra manera, las formas en que los trabajadores se organizan tratan de impactar en los sujetos no trabajadores, la comunidad, el vecindario, las familias, los grupos sociales, así como otras formas asociativas.

No se debe olvidar que esencialmente esta situación refleja una crisis del Estado de bienestar. La minimización de este tipo de Estado muestra, también, una crisis en las relaciones de dominación, ya que el capital se reajusta a nuevas formas de desarrollo, y a su vez, en el mejor de los casos reconstruye las formas de protección y seguridad que pueden ser utilizadas para dirigir y regular a los ciudadanos-trabajadores. Pero en un mundo del trabajo precarizado y de rupturas laborales, en donde las condiciones del trabajo asalariado se conjugan con trabajos atípicos no asalariados, y que está determinado por las leyes del mercado neoliberal hay un regreso de la inseguridad vinculada esencialmente al trabajo (no) asalariado, en la que el trabajador se concebía dentro de una zona de integración, continuando hacia una zona de desafiliación y, finalmente, hacia una zona inestable, de precariedad y vulnerabilidad social (Castel,2010).

Esta inseguridad laboral señala la sensación subjetiva de amenaza o incertidumbre con respecto a continuar trabajando y construir trayectorias laborales estables, es por eso que este tipo inseguridad se amolda como "parte de un proceso de deterioro de las condiciones y percepciones de bienestar, más que un estado determinado, que viven los trabajadores a partir de modificaciones en el mundo del trabajo" (Mancini, 2006, p.2).

Por su parte, Reygadas (2011, p. 270) señala que este tipo de inseguridad implica condiciones de desempleo, subempleo, trabajo precario, riesgo de despido, ausencia de contrato, contratos temporales, trabajo de tiempo parcial, trabajo discontinuo, carencia de prestaciones, precariedad del trabajo, carencia de sistemas de protección contra el desempleo, ausencia o fragilidad de jubilaciones. En esas condiciones es que el trabajador experimenta incertidumbre, desaparece la certeza laboral y la proyección de una trayectoria laboral discontinua.

A pesar de esta condición, los trabajadores continúan ejerciendo su condición de sujetos activos sociales. Crean una identidad compleja donde se agrupan la familia y otros sujetos que indirectamente son parte del trabajo. La nueva forma de identificarse, concebirse y ser percibido influye en el reconocimiento de no pertenecer a una esfera gremial o colectiva tradicional, de no trabajar en tiempos y espacios determinados, por lo que se sitúa dentro de la vulnerabilidad. Sin embargo, esto no muestra una ruptura de los vínculos sociales, familiares o comunitarios, sino que se reestructuran nuevas relaciones laborales, a partir del trabajo y del ejercicio de ciudadanía (Reygadas, 2011, p. 280) $)^{5}$.

Como argumenta Bensusán y Middlebrook (2013) ante los cambios en las formas de negociación e influencia política, que son cada vez menos, los sindicatos y otras formas de organización de trabajadores gremiales, se enfrentan ante riesgos con nuevos instrumentos legales e institucionales, aunado a la misma fragmentación sindical y un limitado pluralismo político en el entorno laboral. En este escenario, es necesario partir de la visión del trabajador "como agente autónomo y en

\footnotetext{
${ }^{5} \mathrm{El}$ autor hace una lectura de Vincent de Gaulejac e Isabel Taboada, y muestra como para el caso mexicano, por ejemplo, se identifican particularidades de la incertidumbre laboral bajo un escenario polarizado; una parte de la población tiene empleos estables y seguros y la mayoría de la población económicamente activa no tiene acceso a trabajos dignos o decentes y sin seguro de desempleo.
} 
control de su entorno; se ejercen derechos a partir de una ciudanía laboral, estado de derechos y protección social universal” (Bensusán, 2010, p. 44). Es decir, se pone a discusión una ciudadanía laboral que, lejos de concesiones laborales, recaen en los derechos como agente autónomo y en control de su entorno; por lo que es pertinente ejercer derechos a partir de una ciudanía laboral, estado de derechos y protección social universal.

Ante ello, a lo que se enfrenta el trabajador actual, es buscar formas imaginativas y operativas de organización y reconocimiento que al menos minimicen la vulnerabilidad y condición de precario. Uno de estas formas es a través de la organización micro y pequeña empresa, el autoempleo y trabajo familiar, el trabajo agrícola no capitalista que agrupa a mujeres y niños, o la informalidad laboral que representa la venta a domicilio y la calle. Estos trabajos tienen el común denominador de tener salarios bajos e inestables, con una amplia rotación, no contar con seguridad social y rupturas en las trayectorias laborales. Esta clase obrera no industrial y atípica, con nuevas características cualitativas, constituye un sujeto que es difícil de sindicalizar empezando porque sus miembros no son asalariados (De la Garza, 2014), pero también por la falta de reconocimiento laboral, así como por la dispersión y cambio continuo en los trabajos.

Todo esto refleja que el neoliberalismo está lejos de brindar y garantizar la prosperidad homogénea y justa en el mundo laboral; no sólo por las recurrentes presencias de las crisis económicas y financieras, sino por la acentuación de graves problemas de desempleo y la consolidación de trabajos en condiciones de informalidad y precarización.

Se observa que, por lo tanto, el neoliberalismo funciona como proyecto de una clase corporativa ante y contra la búsqueda de una hegemonía de la clase trabajadora, por lo que se busca instaurar a través de proyectos políticos e ideológicos un proyecto que modifique y reorganice la concepción del ser humano, la vida social y económica (Harvey, 2014). Pero, más allá de que entre sus características sean la desregulación del mercado de trabajo, la inseguridad laboral y la disminución del papel activo de las organizaciones laborales se percibe una necesidad de situar reivindicaciones laborales y de justicia social y políticas redistributivas mediante formas novedosas de organizaciones de trabajadores (Roca, 2016, p. 9). No es sólo que los sindicatos ya no tengan la capacidad de representación y negociación ante la transformación contemporánea de la organización y producción del trabajo, sino que de manera más incluyente se deben de considerar las intervenciones desreguladoras de los gobiernos y la actitud hostil de las elites empresariales y financieras ante la fuerza de trabajo, tradicional o atípica, formal e informal (Jodar, et. al. 2004).

La acción y organización sindical, o de trabajadores, contemporánea lleva a contemplar procesos y estructuras más amplios, que sean incluyentes en la vida social y establecer una estrategia y agenda de acción viable e incluyente en los trabajos formales, informales y atípicos. Esto es palpable al observar cómo han evolucionado las relaciones laborales y sindicales; por un lado, la coaptación a través de los mecanismos de intervención estatal mediante la política corporativista laboral, desde inicios de la década de los treinta hasta la aplicación del modelo neoliberal en la década de los ochenta del siglo pasado. De acuerdo con Cockroft (2001, p. 58) esta etapa se encuadraba en un colaboracionismo de clase, en donde la militancia creció, pero con profundas raíces de autoritarismo, burocratismo y corporativismo.

Por consiguiente, el modelo neoliberal, y su correlación con el mundo del trabajo actual, demuestra no sólo la crisis laboral, sino también gremial, de organización. En medio de reestructuraciones económicas globales, los trabajadores plantean nuevas formas y acciones de intervención en el mundo.

\section{Critica a la organización laboral: el sindicato entre nuevos sujetos y nuevas acciones}

En el mundo del trabajo las formas más tradicionales de representación se situaron en el sindicato. Este se entendió como una figura sustentada en el derecho laboral que representaba y defendía a la fuerza de trabajo. Sin embargo, su presencia se complejizó no sólo por las reformas laborales excluyentes que lo delimitaron sus acciones, sino también por la intervención y participación en los mercados de trabajo de nuevos sujetos vinculados a nuevos movimientos sociales, cuyos 
métodos de acción y reivindicación, difieren esencialmente de las viejas estructuras tradicionales de organización del trabajador.

El ejemplo latinoamericano, en especial en México, es una muestra clara de lo señalado anteriormente. Los gobiernos implementaron finanzas públicas sanas y restrictivas, políticas salariales de contención, así como mínimas políticas de seguridad y bienestar social hacia los trabajadores asalariados e informales. Por lo que el debilitamiento y poca influencia de las representaciones laborales no incidieron de manera real sobre la política económica y laboral. A esto se suman las condiciones de despolitización, por lo que es mínima la presencia en el activismo y militancia que anteriormente se reflejaba de manera ideológica, partidista y de clase. Así pues, las voces de la clase trabajadora han sido suplantadas por esquemas y discursos completamente individualistas (Székely, 2005).

Para Rubio (2017,p. 47) desde la perspectiva económica, entre mayor sea en nivel de sindicalización mejores serán las condiciones laborales, sin embargo, desde la instauración del modelo neoliberal, aunado a los problemas de corrupción y representatividad, afectaron la membresía sindical, pero esencialmente, la perdida de acción de las organizaciones sindicales fue la incapacidad de resolver los problemas de vulnerabilidad y precarización del trabajo.

Con respecto a los trabajos formales asalariados, gran parte de los contratos colectivos de trabajo han sido flexibilizados también con tendencias a la precarización. Esto a través de las reestructuraciones productivas que modificaron, en nombre de la competitividad y productividad, las características esenciales de empleo y de producción (De la Garza y Neffa, 2001 en De la Garza, 2014).

Conviene subrayar que este contexto obliga a concebir las nuevas formas del trabajo. Por esto, De la Garza (1993) sostiene que los modelos productivos dominantes en todos los sectores económicos se inscriben entre el taylorismo-fordismo y un toyotismo de la precariedad, siendo más visible la división del trabajo. Esta continúa segmentada con bajos salarios, poca inversión en capacitación y alta rotación externa de personal.

Con base a De la Garza $(2011,2014)$ la apertura y reestructuración productiva ha profundizado la polarización del aparato productivo y de servicios, en donde se trata más que segmentos un núcleo central reestructurado, eclético y heterogéneo, en la que se debe de atender las condiciones laborales vulnerables sin representatividad efectiva. Así pues, un modelo sindical moderno debería considerar la estructura y funcionamiento interno, compuesto por simbologías y subjetividades que hacen replantear la condición de democracia no simulada y la participación, así como nuevas articulaciones del trabajo, no sólo el reconocimiento del trabajo clásico, sino con los nuevos trabajos no clásicos, atípicos.

En este punto es nodal en el análisis que se quiere realizar en este escrito: no sólo en reconsiderar a la clase obrera-asalariada, sino la inclusión de un trabajador con nuevas cualidades, un neoproletariado joven, de mujeres y de los migrantes caracterizada por la semicalificación y de bajo nivel salarial, de alta rotación, con una identidad laboral que se reconstruye recurrentemente, pero que no desaparece su esencia de trabajador como sujeto activo que produce y se relaciona socialmente (De la Garza, 2014).

Ahora bien, no se debe de perder de vista el eje neural del sindicato que funciona, con diferentes intensidades, como una organización normativa laboral y social, donde actúa con base a la estrategia y acción de intermediación y negociación, no sólo ante empresa-patronal, sino ser parte dentro de la toma del mundo del trabajo que involucra instituciones gubernamentales y sociales. Por ello, en la reconstitución del sindicalismo y de otras organizaciones gremiales se propone incluir reivindicaciones de corte político, social, cultural y medioambiental. Esta organización de afiliados de trabajadores, cada vez más compleja, debe aspirar a ser la voz de los representados, mediante la combinación de incentivos y elementos de solidaridad, sociabilidad e identidad (Jodar, et. al., 2004, p. 117).

Lo anterior puede dar un salto paradigmático del actuar tradicional del sindicalismo y de otras organizaciones de trabajadores atípicas en la que no sólo se debaten desacuerdos y problemas del 
trabajo, sino que sobrepasan la relación entre afiliados e institución. Cabe señalar que el sindicalismo tiene que volver a prevalecer como una fuerza simbólica de acción colectiva y comunitaria, incorporando en sus reivindicaciones cuestiones de género, el trabajo infantil y la familia, los migrantes, los trabajadores sin base, no afiliados, informales y atípicos. Esto implica gestionar mecanismos de construcción social en el espacio de trabajo para el sujeto colectivo con reconocimiento social.

La incorporación de nuevas necesidades y actores hace que el mundo del trabajo sea complejo, por lo que es necesario, también, establecer alianzas con otras organizaciones comunitarias, barrios y nuevos movimientos sociales que tiene una postura reivindicatoria más allá de lo laboral (Hyman,1997). Por ejemplo, sobre medio ambiente, migración, educación, espacios públicos y cultura democrática.

De allí la crítica hacia los sindicatos tradicionales que continúan centrando su discurso y actividad sólo en el interior de los centros de trabajo. Esta postura lo desvincula hacia nuevas reivindicaciones con otros sujetos insertos en los trabajos y actividades diversas dentro del desempleo, subempleo, la precarización, la vivienda, la dominación de género y el deterioro del medio ambiente (Roca, 2016, p.30). Es decir, engrandecer una cultura organizativa entre trabajador, activista y militante más amplia y de mayor impacto en la intervención y reivindicación. Como afirma Roca (2016, p.35) y Saldívar (2018), esta forma de actuar debe conformar un "sujeto activo" que le permita recuperar la legitimidad social aglutinando elementos étnicos, de género, culturales, políticas públicas y que responden colectivamente más allá de las relaciones laborales. Con respecto a este punto De la Garza (2014) señala que los sindicatos muy gremialistas, sólo interesados en sus problemas y demandad laborales dentro del ámbito laboral deben dejar de ser un sindicato de circulación, sobrepasar el carácter obrerista tradicional, de conciliación de intereses y no de simple defensa, a implementar programas y campañas de acción colectiva y directa más amplias, como la construcción de coaliciones entre las organizaciones sindicales, colectivas y comunitarias.

\section{Una lectura sobre la reorganización del trabajador como acción colectiva}

La globalización muestra que las demandas interrelacionadas con lo cuestión laboral son compartidas de manera mundial, y pueden vincular el carácter social, político y cultural de las organizaciones. En este sentido, cuando se habla de la reorganización del trabajador, se contemplan nuevos esquemas y sujetos que intervienen en esas demandas. Autores como Tarrow (1994) y Tilly y Tarrow (2015) plantean un concepto relacionado con el repertorio de confrontación propio de los movimientos sociales, y está íntimamente relacionado con el supuesto sindical: el de modularidad. Se trata de reproducir diversas formas de lucha, en la cual los sujetos puedan reivindicar otras demandas diversas, relacionadas más allá del mundo del trabajo. Como ejemplo están las uniones europeas de lucha con un proyecto de clase, traspasando la acción sindical como la huelga, pero reafirman el carácter clasista del trabajador (Kuri, 2016, p. 192). De igual forma, ante la incertidumbre y exclusión, la acción colectiva, sustentada en la solidaridad ante conflictos estructurados, funcionan como laboratorios o talleres de gestión obrera y de educación minimizando o desapareciendo, en el mejor de los casos, la incertidumbre laboral (Reygadas, 2011, p.285; Tilly, De la Garza, Sarmiento y Gayosso, 2014). La acción colectiva genera estrategias y gestiones fuera de lo convencional como lo fue la huelga, el paro, la toma o el paro simbólico y otras acciones que tienden a sobreponerse a lo señalado por Sotelo (2015); la tensión social. Estas formas de autogestión, recuperación y negociación, apropiación y reclamo de espacios públicos, así como nuevas formas de reivindicaciones laborales son manifestaciones de una nueva cultura del trabajo.

Para Tarrow (1994 en Kuri, 2016, p.193) el surgimiento de los nuevos movimientos sociales dentro de la contemporaneidad global, significa el inicio de una oleada de protestas colectivas heterogéneas. Es decir, si la nueva agrupación gremial y el trabajador definen gran parte de las reivindicaciones económicas, entonces la (neo) organización sindical o conformada por 
trabajadores, se convertirá en un actor colectivo y puede visualizarse como el iniciador de nuevas reivindicaciones sociales, culturales y políticas, posibilitando la inclusión y conjunción con otros movimientos sociales.

Indiscutiblemente, en este escenario, las formas de trascender de los trabajadores son el espacio público, y no sólo la fábrica o el espacio tradicional de acción, como señala Kuri (2016). Ahora es la calle, el parque o el hogar, que también es donde se trabaja. Estos espacios públicos deben de estar situados en función de: a) la apertura del acceso a la participación en sistemas políticos; b) cambios en las fuerzas políticas; c) capacidad de generar nuevos aliados y d) involucramiento con las elites existentes (Tarrow, 1994 en Kuri, 2016, p. 193).

Hay que mencionar, además, que las nuevas y modernas formas de movilización del trabajador permitirán redefinir el principio de identidad del sindicalismo y de otras formas de organización. Es decir, su reconocimiento se reconstruye a través del conflicto, de centrar las desigualdades y vulnerabilidades, por el cual constituye y organiza a los sujetos heterogéneos. Estos actores colectivos son definidos a partir del campo de relaciones sociales estableciendo el principio de oposición; conformándose a partir del mismo conflicto, sólo si el sujeto se siente confrontado, le permite actuar y orientar su disputa más allá de su vida laboral (Kuri, 2016, p.197).

Las nuevas formas de organización del trabajador, algunos en el contexto sindical, deben de enmarcarse en nuevos movimientos sociales que son respuestas colectivas encauzadas a defender los diversos mundos de vida. Anteriormente, mientras en la etapa del capitalismo industrial el conflicto era delimitado entre la burguesía y la clase trabajadora, ahora esa situación se expande a la sociedad civil, que reivindica elementos subjetivos como la solidaridad, el derecho a la felicidad y al buen vivir, aunado a proyectar una trayectoria laboral continua y estable (Kuri, 2016, 198). Enmarcar esta postura que incluye la solidaridad, no vista como una simple ayuda, sino una forma de autoreconocerse como parte del orden social. Esa forma de concebirse conlleva a una ruptura, o a una consolidación, de los límites de compatibilidad del sistema de relaciones sociales y culturales (Melucci y Massolo, 1991; Melucci,1994).

Si bien no es la intención de correlacionar mecánicamente la organización del trabajador con la vida social, si es necesario plantear que los nuevos movimientos sociales obligan a reconsiderar una organización histórica como lo ha sido el sindicato. Sus formas de acción en lo social y no sólo en laboral, otorga diferentes visiones sobre el sentido de las luchas de un mundo con marcadas desigualdades; permite, como subraya Antunes (2013) en darle nuevos sentidos al trabajo a escala global en la que participan hombres, mujeres, personas mayores, nacionales e inmigrantes, diferentes razas, indígenas, pobres urbanos, trabajadores calificados o descalificaos, estables y precarios, es decir, tener una mirada transversal y multifacética del trabajador actual.

En estas crisis recurrentes, con cambios en la producción y organización en el mundo laboral, es válido plantear, entonces, nuevas formas de ser trabajador y novedosos esquemas de organizaciones gremiales. Así pues, la metamorfosis del mundo del trabajo lleva a ubicar ya no sólo al trabajador que labora por un tiempo y en un espacio determinado por un salario estipulado en un contrato, sino como sostiene Antunes (2013, p. 21) los cambios llevan a postular una nueva polisemia del trabajo; trabajadores tercerizados, subcontratados y temporarios amoldándose a la empresa flexible, son heterogéneos por su condición de género, etnia, generación y nacionalidad. Lo que los homogeniza es la falta de seguridad laboral y social.

Lo anterior sobrepasa los requisitos en la cual la condición de trabajador sólo está en función de indicadores que moldea el capitalismo contemporáneo, como son la competitividad, productividad y la competencia (Harvey, 2014). Asimismo, es dar reconocimiento a la clase trabajadora, situada en otro contexto, con una globalización consolidada, sin importar su condición de género, raza y calificación, que sistemáticamente, por sus condiciones de precariedad y vulnerabilidad los homogeniza, de allí la necesidad de una solidaridad transnacional con nuevos tipos de articulación en la organización, representación y acción (Hyman, 1997). No se debe de olvidar el rol de las instituciones que marcan el funcionamiento en la vida del trabajo y la organización de la producción. Es decir, el neoliberalismo ha desvinculado la relación entre el Estado y la protección 
al trabajador-ciudadano, por lo que es necesario criticar el rol del Estado social, y que desde la perspectiva de Castel (2010) sea capaz de proteger al ciudadano-trabajador ante la inseguridad social, el desempleo y minimizar las incertidumbres de la vida cotidiana, a partir de vínculos sociales para evitar la disolución social como características de la etapa del capitalismo contemporáneo.

Por ello, entre los desafíos del sindicalismo en México, y demás organizaciones con representación gremial, está instaurar el valor del pluralismo ideológico y político, buscando mayor representatividad y respaldo social, vinculado con otras organizaciones que, directa o indirectamente, van de la mano con reivindicaciones de carácter global, es decir, laboral, cultural y ambientales (Giménez, 2019).

Finalmente, se observa, pues, que el programa socioeconómico y político dentro de la globalización y el neoliberalismo, ha convertido un Estado pasivo, donde se ejercen negativamente, formas de exclusión y violencia laboral. Es decir, hay una ampliación mundial de la salarización y explotación del trabajador que se traduce en precariedad laboral, pero ahora la figura del asalariado es más heterogénea e indefensa, con identidades redefinidas, donde incorpora nuevos espacios y circuitos laborales desregulados que moldean la dinámica del capital. Asimismo, los cambios en las formas organizacionales y laborales, no sólo de la industria, sino de otros sectores económicos, conllevan a emerger una postura de los trabajadores en defesa de mejores condiciones laborales, y que se amplía a otros derechos, ya no sólo como trabajador sino como ciudadanos. Por último, las relaciones contemporáneas entre capital y trabajo generaron, también, una reconfiguración del poder del trabajador ante la figura patronal y del Estado, como resultado histórico del régimen de acumulación flexible ante nuevas e incluyentes demandas y reivindicaciones.

\section{Conclusiones}

Los cambios en los sistemas de producción y consumo, a partir de la consolidación de la globalización económica, trastocaron las formas tradicionales de organización de los trabajadores que en su momento permitieron establecer formas de defensa, representación y socialización en sus relaciones labores y sociales. Dentro de los cambios se presentan nuevos elementos de carácter administrativo que llevan a situar los esquemas laborales en función de la eficiencia, competitividad y productividad vinculada en la calificación. Otro de los cambios fue la instauración de un modelo de flexibilidad que conlleva, no sólo a la polivalencia en las labores del trabajador, sino a su inestabilidad y dificultad de ofrecer oportunidades individuales, y de continuidad, en los esquemas colectivos de acción. Es decir, ahora el trabajador presenta diferencias cualitativas en los mundos del trabajo; hay otra forma no sólo de trabajar, ya sea por los avances tecnológicos, sino también, por cuestiones organizacionales que exigen establecer nuevos consensos, más plurales e incluyentes que conformaran un nuevo tipo de relaciones y organizaciones que articulen diferentes niveles de decisión y formas de acción sobre la sociedad por parte de trabajadores y ciudadanos; entre trabajadores y sociedad civil.

Así pues, ante los cambios que demanda la dinámica del capitalismo, el movimiento sindical, los nuevos movimientos y organizaciones de trabajo, bajo la continuidad de la membresía tradicional, se han visto afectado por el crecimiento del empleo no estructurado, el trabajo precario e inestable o el autoempleo que generalmente es informal y que hace difícil de sindicalizar y organizar. Ante esto, y por la misma metamorfosis de las relaciones laborales y sociales, hay modificaciones recurrentes en las formas de representación de la fuerza de trabajo con nuevas exigencias ante la cotidianidad. Las nuevas reivindicaciones laborales, a tres décadas del neoliberalismo, hacen ver que desde el punto de vista sindical y de otro tipo de organización del trabajador, están siendo respondida de manera parcial, pero dinámica, a través de novedosas formas de organización sustentadas en las acciones colectivas con trabajadores tradicionales y atípicos en conjunción con otras demandas ciudadanas que van más allá del contexto laboral. La continuidad del neoliberalismo, y sus efectos en la precarización del trabajo, genera nuevas oportunidades para concretar organizaciones o colectivos gremiales independientes, en concordancia con 
movimientos sociales contemporáneos que garanticen el logro de sus reivindicaciones con diferentes magnitudes y trascendencias.

\section{Referencias bibliográficas}

Antunes, Ricardo (2013). Los sentidos del trabajo. Ensayo sobre la afirmación y negación del trabajo. Herramienta ediciones. Argentina.

Bensusán, Graciela (2010). Ciudadanía, Estado de derecho y reforma laboral en México. Repensando el modelo de protección social para el siglo XXI. En Arteaga, Arnulfo (Coord.) Trabajo y Ciudadanía. Una reflexión necesaria para la sociedad del siglo $\boldsymbol{X X I}$. Porrua. México.

Bensusán, Graciela y Middlebrook, Kevin (2013). Sindicatos y política en México: cambios, continuidades y contradicciones. UAM-CLACSO-FLACSO. México.

Castel, Robert (2010). El ascenso de las incertidumbres. Trabajo, protecciones, estatuto del individuo. Fondo de Cultura Económica. México.

Cerdas, Juan Manuel (2014). El clientelismo político: una revisión del concepto y sus usos. Anuario de Estudios Centroamericanos, núm. 40. Costa Rica. (Pp. 311- 338).

Cockroft, James (2001). América Latina y Estados Unidos: Historia y política país por país. Siglo XXI editores. México.

De la Garza, Enrique (1993). Restructuración productiva y respuesta sindical en América Latina. Sociología del trabajo, $\mathrm{N}^{\circ} 19$. España. (Pp.142-155).

De la Garza, Enrique (2011). Trabajo no clásico, organización y acción colectiva. En Trabajo no clásico, organización y acción colectiva Tomo II. UAM-Plaza y Valdés editores. México.

De la Garza, Enrique (2014). El Sindicalismo, el empleo formal y su relación con el Estado en América Latina. I Coloquio internacional de Políticas y derechos de las personas trabajadoras, Quito, Ecuador.

Escobar, Saúl (2019). El sindicalismo mexicano: ¿hacia un nuevo pacto social? En EconomíaUNAM. Vol. 16, No 46. México. (Pp. 241-259). DOI: https://doi.org/10.22201/fe.24488143e.2019.46.449

Gilly, Adolfo (2014). El tiempo del despojo. Poder y territorio. Conferencia en el Foro E1 Poder Hoy, Cátedra Alain Touraine. Universidad Iberoamericana. Puebla México.

Giménez, Luis Emilio (2019). ¿Hay futuro para el sindicalismo mexicano? Los desafíos de un nuevo contexto legal y político. Fundación Friedrich Ebert-México. México.

Harvey, David (2014). El neoliberalismo es un proyecto de clases. Extraido de https://marxismocritico.com/2014/10/24/el-neoliberalismo-es-un-proyecto-declase-entrevista-a-david-harvey-en-bolivia/. Consulta: 20/05/2016.

Hyman, Richard (1997). Trade unions and interest representation in the contexts of globalization. $\begin{array}{lllll}\text { Transfer. } & \text { vol. 3). U.K. (Pp. 515-533). DOI: }\end{array}$ https://doi.org/10.1177\%2F102425899700300306

Jodar, Pere; Martín-Artiles Antonio; Alós, Ramón (2004). El sindicato hacia dentro. La relación entre la organización y los trabajadores desde el análisis de la afiliación. Revista Papers. Revista de Sociología. $\quad N^{\circ}$. 72. España. (Pp.113-144). DOI: $\underline{\text { http://dx.doi.org/10.5565/rev/papers/v72n0.1128 }}$

Kuri, Edith (2016). El carácter multidimensional de la acción colectiva y los movimientos sociales: una problematización teórica. Secuencia No. 95. México. (Pp.188-214). DOI: http://dx.doi.org/10.18234/secuencia.v0i95.1382

Lorey, Isabell (2016). Estado de inseguridad. Gobernar la precariedad. Traficantes de sueños. España.

Mancini, Fiorella (2006). Subjetividad e Incertidumbre. Experiencias de la inseguridad laboral en México. V Congreso Nacional AMET 2006. Trabajo y reestructuración. Morelos, México. 
Melucci, Alberto (1994). Asumir un compromiso: identidad y movilización en los movimientos sociales. Zona Abierta. N69. España. (Pp.153-180).

Melucci, Alberto y Massolo, Alejandra (1991). La acción colectiva como construcción social. Estudios Sociológicos. Vol 9, N² 26. México. (Pp.357-364).

Negri, Antonio y Hardt, Michael (2002). Imperio. Paidós. España.

Ortega, Max y Solís de Alba, Ana Alicia (2005). Estado, crisis y reorganización sindical. ITACA. México.

Reygadas, Luis (2011). La experiencia de la incertidumbre. En Pacheco, Edith, De la Garza, Enrique y Reygadas, Luis (Coords.). Trabajos atípicos y precarización del empleo. COLMEX. México.

Roca, Beltrán (2016). Transformaciones en el trabajo y movimiento sindical. Propuestas para una renovación necesaria. Estudios del Progreso. $N^{\circ}$ 86, Fundación Alternativas. España. (Pp. 1-49).

Rodríguez, Octavio (2009). México, proceso y afianzamiento de un nuevo régimen político.

Andamios. Vol. 6, No11. México. (Pp. 205-234). Extraído de http://www.scielo.org.mx/scielo.php?script=sci arttext\&pid=S18700063200900020000 9\&lng=es\&tlng=es. Consulta 22/06/2019.

Rubio, Jesús (2017). Sindicalización y precariedad laboral en México. Región y Sociedad. Volumen XXIX, $\quad \mathrm{N}^{\mathrm{o}}$ 68. México. (pp.37-75). DOI: https://doi.org/10.22198/rys.2017.68.a247

Saldívar, Américo (2018). Los saldos del neoliberalismo. La Jornada. Extraído de http://www.jornada.com.mx/2018/07/01/opinion/024a1mun. Consulta:12/11/2018.

Sotelo, Adrián (2015). El precariado ¿nueva clase social? M.A. Porrua-UNAM, Fundación de Investigaciones Sociales y Política. México.

Székely, Miguel (2005). La importancia de contar con una medición oficial de pobreza en México. En Miguel Székely (Coord.). Números que mueven al mundo: la medición de la pobreza en México. SEDESOL-M.A. Porrúa. México.

Tarrow, Sidey (1994). El poder en movimiento. Los movimientos sociales, la acción colectiva y la política. Alianza editorial. España.

Tilly Charles, De la Garza, Enrique; Sarmiento, Hugo y Gayosso José Luis (2014).Los trabajadores que se organizan en la plaza: contra-movimiento de una fuente inesperada. Revista de Economía Crítica. No18. España (Pp. 160-180). Extraído de http://revistaeconomiacritica.org/sites/default/files/revistas/n18/10 Tilly-Garz. Consulta:16/02/2017.

Tilly, Charles and Tarrow, Sidney (2015). Contentious politics (Second edition). Oxford University Press. USA.

Zapata, Francisco (2000). El sindicalismo y la política laboral en México. Región y Sociedad. Vol. XII. N¹9, México. (Pp.3-29). DOI: https://doi.org/10.22198/rys.2000.19.a753 